\title{
HLA-DQA1*1 contributes to resistance and A1*3 confers susceptibility to Type 1 (insulin-dependent) diabetes mellitus in Japanese subjects
}

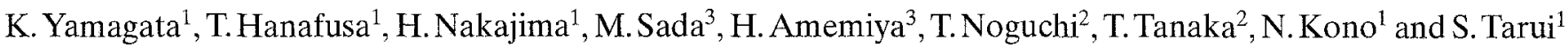 \\ ${ }^{1}$ The Second Department of Internal Medicine, ${ }^{2}$ Department of Nutrition and Physiological Chemistry, Osaka University Medical \\ School, and ${ }^{3}$ National Cardiovascular Center, Research Institute, Department of Surgical Research, Osaka, Japan
}

\begin{abstract}
Summary. In this study HLA-DQA1 and TNF genes in addition to HLA-DQB1 gene were investigated at DNA level for elucidation of the genetic backgrounds of Type 1 (insulin-dependent) diabetes mellitus in Japanese subjects. DNA, amplified by polymerase chain reaction, was subjected to allele specific oligonucleotide dot blot analysis, restriction fragment length polymorphism analysis or DNA sequencing. Polymorphism of the TNF gene to Ncol did not correlate with Type 1 diabetes in Japanese patients. DQw1.2 had a protective effect against the disease, the DQA $1 * 1$ allele was significantly decreased and DQA $1 * 3$ allele was significantly increased. Seventeen out of twenty-two Type 1 diabetic
\end{abstract}

patients $(77 \%)$ were homozygous for DQA $1 * 3$ and five out of twenty-two $(23 \%)$ heterozygous. The DQA $1 * 3$ gene of Type 1 diabetic patients had a normal nucleotide sequence. Furthermore, DQA $1 * 3$ was found unexpectedly in two patients without DR4 or DR9. These data indicate that DQA1 gene confers susceptibility and resistance to Type 1 diabetes in Japanese subjects.

Key words: Type 1 (insulin-dependent) diabetes mellitus, HLA-DQA1 gene, HLA-DQB1 gene, tumour necrosis factor, polymerase chain reaction-restriction fragment length polymorphism (PCR-RFLP).
Type 1 (insulin-dependent) diabetes mellitus is considered to be an autoimmune disease. Several genetic factors contribute to the pathogenesis of Type 1 diabetes, and human leucocyte antigen (HLA) genes are of great importance in occurrence of the disease. Recent studies at DNA level have shown that aspartic acid (Asp) at position 57 of the HLA-DQ $\beta$ chain protects against Type 1 diabetes and non-aspartic acid (non-Asp) at the same position predisposes to the disease in Caucasians [1]. Recently however, we have proved that about half the Japanese Type 1 diabetic patients are homozygous for Asp at this position [2]. This finding indicates that firstly, other genetic markers such as the TNF gene should be explored in Japanese Type 1 diabetic patients and secondly, DQA1 gene should also be examined in relation to the antigen presenting function of the DQ $(\alpha-\beta)$ molecule. Thus, we have investigated HLA-DQA1, DQB1 and TNF genes in Japanese subjects.

\section{Subjects and methods}

\section{Patients and controls}

Twenty-two unrelated Type 1 diabetic patients attending the Second Department of Internal Medicine of Osaka University Medical School Hospital were studied. All patients were diagnosed clinically according to the criteria of WHO and were on insulin therapy.
Thirty-two control subjects were randomly selected from our staff. Informed consent was obtained from all patients and healthy control subjects. This work was performed in accordance with the principles of the Declaration of Helsinki. Serological HLA typing was done by the NIH microlymphocytotoxicity test.

\section{Polymerase chain reaction (PCR)}

Genomic DNA was extracted from peripheral lymphocytes and about one microgram was subjected to PCR using 2.5 units of Taq DNA polymerase (AmpliTaq, Perkin-Elmer/Cetus, Norwalk, Ct., USA). Reaction conditions were performed as per the manufacturer's recommendations. Amplification was performed by 30 cycles of denaturation $\left(94^{\circ} \mathrm{C}\right)$, annealing $\left(60^{\circ} \mathrm{C}\right)$ and polymerization $\left(72^{\circ} \mathrm{C}\right)$. Oligonucleotides were synthesized by a DNA synthesizer (Model 381A, Applied Biosystems, Inc., Foster City, Calif., USA). TNFP1 (5'-GCACAGCAGGTGAGGCTCTCC-3') and TNFP2 (5'-GGTGGTGCCACACACCCTTGG-3') were used as PCR primers for TNF gene amplification. DQAP1 (5'GCCTCTTACGGTGTAAACTTG-3') and DQAP2 (5'-ATTGGTAGCAGCGGTAGAGTT-3') were used for HLA-DQA1 gene amplification. HLA-DQB1 was amplified using DQP1 and DQP2 as reported previously [2].

\section{PCR-RFLP and PCR-ASO methods}

Amplified DNA was analysed by restriction fragment length polymorphism (RFLP) or allele specific oligonucleotide (ASO) dot blot methods. Polymorphism of NcoI site in TNF- $\beta$ gene has been pre- 


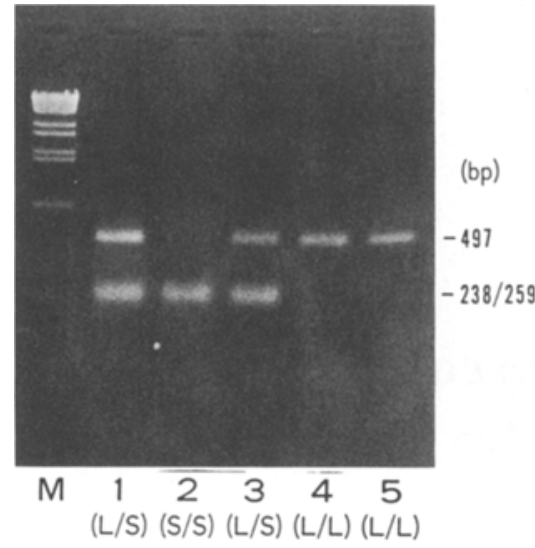

viously reported [3]. DNA fragment (497 base pairs; bp) including this polymorphic site was amplified and one tenth of the reaction mixture was digested with 10 units of NcoI (Takara shuzo, Kyoto, Japan) for $3 \mathrm{~h}$ at $37^{\circ} \mathrm{C}$. The digested sample was subjected to $2 \%$ agarose-gel electrophoresis and stained with ethidium bromide. Amplified HLA-DQA1 gene was digested with HaeIII and DdeI. Digested fragments were detected as described above. HLA-DQA1 genotyping (DQA $1 * 1, * 2, * 3$ and $* 4$ ) was decided by the RFLP patterns as described in detail by Maeda et al. [4]. In brief. HaeIII digestion of DQA $1 * 1, * 2, * 3, * 4$ yields $44+76+117 \mathrm{bp}, 44+190 \mathrm{bp}, 237 \mathrm{bp}$ and $44+190 \mathrm{bp}$, respectively. DQA $1 * 2$ and $* 4$ can be classified by DdeI (DQA $1 * 2 ; 98+136 \mathrm{bp}$, DQA $1 * 4 ; 107+127 \mathrm{bp}$ ). HLA-DQB1 genotyping was decided using ASO probes (DQ1.1, DQ1.2, DQ1.9, DQ1.AZH, DQ3.1, DQ3.2, DQ3.1-26, DQ3.3-26, DQ4 and DQ2 (5'-GCTGGGGCTGCCTGCCG-3') ) [2]. DQw1.12 was identified using DQ1.9 and DQ3.1-26 probes. Hybridization and washing conditions are described elsewhere [2].

\section{DNA sequencing}

Amplified DNA fragments were isolated after separation by $8 \%$ polyacrylamide gel electrophoresis and subcloned to the HincII site of pUC119 vector. M13 universal primers and PCR primers were used as sequencing primers in dideoxy methods. To exclude the PCR errors, three to six individual clones were sequenced following the WHO Nomenclature Committee recommendation.

\section{Statistical analysis}

The statistical differences were assessed by Fisher's exact test and the calculation was performed using SAS statistical analysis programme.

\section{Results}

A portion of TNFB gene ( $497 \mathrm{bp}$ ) was amplified and these fragments were digested with NcoI. RFLP patterns are shown in Figure $1 \mathrm{~A}$. Homozygosis for NcoI site negative and homozygosis for NcoI site positive yielded $497 \mathrm{bp}(\mathrm{L})$ and $238 / 259 \mathrm{bp}$ (S) fragments, respectively. Heterozygosis for NcoI yielded L and S fragments. Two short fragments (238 and 259bp) were detected as only one band in this gel electrophoresis condition. The upper left part of Table 1 shows the summary of NcoI polymorphism of TNF $\beta$ gene. There was no difference in frequency of NcoI polymorphism between the Type 1 diabetic patients and control subjects.

This NcoI polymorphic site is located in the first intron of TNF $\beta$ gene [3]. The amplified fragments from three individuals homozygous for $\mathrm{L}$ (one control subject and two Type 1 diabetic patients) were sequenced. A single base transition at NcoI site (from CCATGG to CCATG $\underline{A}$ ) was observed in these three individuals.

HaeIII digestion of DQA1 gene is shown in Figure $1 \mathrm{~B}$. Polymorphic patterns of homozygosis for $\mathrm{A} 1 * 1$ and $A 1 * 3$ are shown in lanes 1 and 2, and $A 1$ heterogeneity can be analysed by summation of these patterns (lanes 3 and 4). In lanes 5 and 6, only 237bp fragment was detected. This indicates that these two patients (lanes 5 and 6) were both homozygous for A $1 * 3$ although they had neither DR4 nor DR9 (DR11/13 and DR8/14). Although

Table 1. Frequencies of TNF, HLA-DQA1 and HLA-DQB1 alleles in Japanese Type 1 (insulin-dependent) diabetic patients $(n=22)$ and control subjects $(n=32)$

\begin{tabular}{|c|c|c|c|c|c|c|c|}
\hline TNF allele & $\begin{array}{l}\text { Patients } \\
n(\%)\end{array}$ & $\begin{array}{l}\text { Control subjects } \\
n(\%)\end{array}$ & $p$ values & DQB1 allele & $\begin{array}{l}\text { Patients } \\
n(\%)\end{array}$ & $\begin{array}{l}\text { Control subjects } \\
n(\%)\end{array}$ & $p$ values \\
\hline $\mathrm{L} / \mathrm{L}^{\mathrm{a}}$ & $11(50)$ & $16(50)$ & NS & DQw1.1 & $6(13.6)$ & $6(9.4)$ & $\mathrm{NS}^{*}$ \\
\hline $\mathrm{L} / \mathrm{S}^{\mathrm{b}}$ & $10(45.5)$ & $14(43.8)$ & NS & DQw1.2 & $0(0)$ & $7(10.9)$ & $0.040^{*}$ \\
\hline \multirow[t]{2}{*}{$\mathrm{S} / \mathrm{S}$} & $1(4.5)$ & $2(6.2)$ & NS & DQw1.12 & 1 (2.2) & $6(9.4)$ & NS \\
\hline & & & & DQw1.9 & $0(0)$ & $1(1.6)$ & NS \\
\hline \multirow{2}{*}{\multicolumn{4}{|c|}{ DQA1 allele }} & DQw1.AZH & $1(2.2)$ & 1 (1.6) & NS \\
\hline & & & & DQw2 & $0(0)$ & $0(0)$ & NS \\
\hline A1 & $4(9.1)$ & $23(35.9)$ & $0.001 * *$ & DQw4 & $9(20.5)$ & $10(15.6)$ & NS \\
\hline A2 & $0(0)$ & $0(0)$ & NS & DQw7 & $4(9.1)$ & $6(9.4)$ & NS \\
\hline A3 & $39(88.6)$ & $35(54.7)$ & $0.000^{* *}$ & DQw8 & $3(6.8)$ & $0(0)$ & $\mathrm{NS}^{\mathrm{c}}$ \\
\hline A4 & $1(2.3)$ & $6(9.4)$ & NS & DQw9 & $14(31.8)$ & $11(17.2)$ & NS \\
\hline
\end{tabular}

a L, NcoI negative; ${ }^{\mathrm{b}} \mathrm{S}$, Ncol positive; ${ }^{\mathrm{c}} p<0.05$ (uncorrected); $*$ and $* *$ indicate $p<0.05$ and $p<0.01$, respectively. Frequencies of DQB1 allele were calculated as follows: when the result of polymerase chain reaction-allele specific oligonucleotide analysis was $\mathrm{X} /-, \mathrm{X}$ was counted only once 
unexpected DQA genotypes were also observed in a few control subjects (e.g. DR1/ㅇ-DQA1/ㄱ) on one allele, such unusual association to DQA $1 * 3$ was not found on both alleles in control subjects. Seventeen out of $22(77 \%)$ Type 1 diabetic patients were homozygous for the DQA $1 * 3$ allele and 5 out of $22(23 \%)$ were heterozygous. In contrast, only 11 of $32(34 \%)$ control subjects were homozygous for the DQA $1 * 3$ allele. All Type 1 diabetic patients had DQA $1 * 3$ at least on one allele. Frequency of HLA-DQA1 alleles in Japanese Type 1 diabetic patients and control subjects are shown in the left lower part of Table 1 . A1*3 was significantly increased $\left(p=0.000^{* *}\right)$ and $\mathrm{A} 1 * 1$ was significantly decreased $\left(p=0.001^{* *}\right)$ in Type 1 diabetes mellitus. Decreased frequency of $A 1 * 4$ was observed in the patients, but was not significant.

To further investigate whether the unique sequence variation in DQA $1 * 3$ gene could be observed or not in the Type 1 diabetic patients, amplified DNA fragments from three DR4/DR4, one DR11/13 (lane 5, Fig. 1B) and one DR8/14 (lane 6, Fig. 1B) Type 1 diabetic patients were sequenced but the unique sequence was not detected.

Frequencies of DQB1 alleles are also shown on Table 1. When the result of PCR-ASO analysis was X/-, X was counted only once. Increased frequencies were observed in DQw1.1, DQw8 (DQw3.2), DQw9 (DQw3.3) and DQw4, but they were not significant in this study. On the other hand, DQw1.2 was significantly decreased $\left(p=0.040^{*}\right)$ in Type 1 diabetes.

\section{Discussion}

TNF gene is located in HLA region (class III) and polymorphism of Ncol site in TNF $\beta$ (not TNF $\alpha$ ) has been established [3]. Badenhoop et al. pointed out the increase of the heterozygosity of this site in Caucasian patients [5]. However, as shown in Table 1, the frequency did not differ between the control subjects and Type 1 patients in our study. Thus, this polymorphism itself seems to have little influence on manifestation of the disease in Japanese. Besides, amplified DNA sequences of the NcoI site negative type in two patients and one control subject were identical to the sequence which was previously published [3] and thus it was not unique to Type 1 diabetes.

The participation of HLA-DQA1 to Type 1 diabetes has been suggested in Black [6], Japanese [7] and Caucasian subjects [8]. Particularly in Japanese subjects the increase of DQA $1 * 3$ allele and the decrease of DQA $1 * 4$ have been reported previously with PCR-ASO methods [7]. PCR-RFLP methods could type the DQA1 allele easily and rapidly with appropriate restriction endonucleases [4]. Moreover, whether the individual is homozygous or heterozygous can be decided by the patterns of digestion. Using this system, our results demonstrated the increase of DQA $1 * 3$ allele in Type 1 diabetic patients. In addition, this study has clearly shown for the first time in Japanese Type 1 diabetic patients, that the DQA1*1 allele was significantly decreased. The frequency of the DQA $1 * 4$ allele did not differ significantly between Type 1 diabetic patients and control subjects. So DQA $1 * 1$ seems to have a protective effect against Type 1 diabetes in Japanese subjects. The DQA $1 * 1$ gene is in linkage disequilibrium with DR1, 2, w6 and w8 [4]. The decrease of the DQA1*1 allele in patients may reflect the decrease of DR2 in Type 1 diabetic patients. Sequence analysis revealed that DQA $1 * 3$ allelic sequence of Japanese Type 1 diabetic patients is identical to that reported previously [4]. Since DQA $1 * 3$ is in linkage disequilibrium with DR4 and DR9 [4], the high frequency of DQA $1 * 3$ may be accounted for by the linkage with DR4 and DR9. However, we noticed two patients who have neither DR4 nor DR9 but were homozygous for DQA $1 * 3$ (Fig. 1B). Their DQA types were reconfirmed by DNA sequencing. Though the observed patient number is only two and the unexpected association between DQA1*3 and non-DR4 or DR9 was detected on one allele of a few control subjects, our finding suggests the principal role of DQA1*3 gene in susceptibility to the disease. The decreased frequency of the DQA $1 * 1$ allele and increased frequency of the DQA $1 * 3$ allele strongly suggest that HLA-DQA1*1 contributes to resistance and A1*3 confers susceptibility to Type 1 diabetes in Japanese subjects.

DQB1 alleles were also investigated in a larger number of subjects than our previous report [2]. Increased frequencies were observed in DQw1.1 (non-Asp), DQw8 (non-Asp), DQw9 (Asp) and DQw4 (Asp) in Type 1 diabetes, although they were not significant. DQw1.2 (Asp) was significantly decreased $(p=0.040 *)$ in Japanese patients as Awata et al. reported recently [9]. This protective effect of DQw1.2 was not observed by Todd et al. [7], who studied Japanese patients who developed the disease under the age of 16 years. The difference in the age of onset may be a possible explanation for the different incidence of DQw1.2, since most of our patients developed the disease at over the age of 16 years.

In this study we have shown the importance of DQA $1 * 3$ in Japanese Type 1 diabetic patients. However, whether the DQA1*3 gene itself or an unknown gene in linkage with DQA1 is responsible remains to be resolved. Recently, a study with I-A transgenic NOD mice [10] indicated the significance of I-A $\alpha$ (corresponding to human $D Q \alpha$ ) chain in the development of diabetes. This result supports that DQA1 gene itself is important for genetic susceptibility to Type 1 diabetes.

Recently DQ molecules consisting of Arg 52 residuebearing $\alpha$ chain and non-Asp 57 residue-bearing $\beta$ chain were suggested as being susceptible in Caucasian patients [8]. In Japanese Type 1 patients, a combination of DQA1*3 (Arg 52) $\alpha$ chain and DQw4 and/or DQw9 (Asp 57) $\beta$ chain is predominant in our study. Although the combination of responsible $\alpha-\beta$ dimer is different, these data indicate the importance of considering the whole DQ molecule.

Given the fact that class II MHC molecules can present antigens to $\mathrm{T}$ cells, three-dimensional configuration of a class II MHC $\alpha$ - $\beta$ dimer is important for its interaction with antigens as well as to $T$ cell receptors. In this context, future research should investigate the function of a class II MHC $\alpha-\beta$ dimer to clarify the pathogenic mechanism of Type 1 diabetes mellitus.

Acknowledgements. We thank Dr. H.Inoko, Mr. M. Inoue, Dr. T. Yamasaki, Dr. M. Takenaka, Mr. K. Yamada for their advice and 
Mr. T. Tanaka for preparing the oligonucleotides. This study was supported by the Scientific Research Fund from the Ministry of Education, Science and Culture of Japan and the grant from Insulin Study Group.

\section{References}

1. Todd JA, Bell JI, McDevitt HO (1987) HLA-DQ $\beta$ gene contributes to susceptibility and resistance to insulin-dependent diabetes mellitus. Nature 329:599-604

2. Yamagata K, Nakajima H, Hanafusa T, Noguchi T, Miyazaki A, Miyagawa J, Sada M, Amemiya H, Tanaka T, Kono N, Tarui S (1989) Aspartic acid at position 57 of DQB chain does not protect against Type 1 (insulin-dependent) diabetes mellitus in Japanese subjects. Diabetologia 32: 762-764

3. Nedospasov SA, Shakhov AN, Turetskaya RL, Mett VA, Azizov MM, Georgiev GP, Korobko VG, Dobrynin VN, Filippov SA, Bystrov NS, Boldyreva EF, Chuvpilo SA, Chumakov AM, Shingarova LN, Ovchinnikov YA (1986) Tandem arrangement of genes coding for tumor necrosis factor (TNF- $\alpha$ ) and lymphotoxin (TNF- $\beta$ ) in the human genome. Cold Spring Harbor Symposia on Quantitative Biology, Vol LI: 611-624

4. Maeda M, Murayama N, Ishii $\mathrm{H}$, Uryu N, Ota M, Tsuji K, Inoko H (1990) A simple and rapid method for HLA-DQA1 genotyping by digestion of PCR-amplified DNA with allele specific restriction endonuclease. Tissue Antigens 34: 290-298

5. Badenhoop K, Schwarz G, Trowsdale J, Lewis V, Usadel KH, Gale EAM, Bottazzo GF (1989) TNF- $\alpha$ gene polymorphisms in Type 1 (insulin-dependent) diabetes mellitus. Diabetologia 32: $445-448$
6. Todd JA, Mijovic C, Fletcher J, Jenkins D, Bradwell AR, Barnett AH (1989) Identification of susceptibility loci for insulin-dependent diabetes mellitus by trans-racial gene mapping. Nature 338: 587-589

7. Todd JA, Fukui Y, Kitagawa T, Sasazuki T (1990) The A3 allele of the HLA-DQA1 locus is associated with susceptibility to type 1 diabetes in Japanese. Proc Natl Acad Sci USA 87: 10941098

8. Khalil I, D'Auriol L, Gobet M, Morin L, Lepage V, Deschamps I, Park MS, Degos L, Galibert F, Hors J (1990) A combination of HLA-DQ $\beta$ Asp57-negative and HLA-DQ $\alpha$ Arg52 confers susceptibility to insulin-dependent diabetes mellitus. J Clin Invest 85: 1315-1319

9. Awata T, Kuzuya T, Matsuda A, Iwamoto Y, Kanazawa Y, Okuyama M, Juji T (1990) High frequency of aspartic acid at position 57 of HLA-DQ $\beta$-chain in Japanese IDDM patients and nondiabetic subjects. Diabetes 39: 266-269

10. Miyazaki T, Uno M, Uehira M, Kikutani H, Kishimoto T, Kimoto M, Nishimoto H, Miyazaki J, Yamamura K (1990) Direct evidence for the contribution of the unique I-A NoD to the development of insulitis in non-obese diabetic mice. Nature 345: 722-724

Received: 13 August 1990

Dr. K. Yamagata

The Second Department of Internal Medicine

Osaka University Medical School

1-1-50 Fukushima, Fukushima-ku

Osaka 553

Japan

\section{Announcements}

\section{Do It \\ Diabetes Care Optimization Through Information Technology - Study Group of the EASD}

This initiation and first annual meeting will be held on April 24-26, 1991 in Gubbio, Perugia, Italy. Those interested in participating the study group or the initiation workshop are requested to submit a short position statement ( 200 words) on their field of interest, previous work in the field and on their potential contribution to the workshop. For further information please contact: Prof. M. Massi-Benedetti, University of Perugia, Via Enrico dal Pozzo, I-06100 Perugia, Italy. Correspondence for the Study Group:Dr.Dr. Klaus Piwernetz, Diabetescenter Bogenhausen, 3. Med. Abt., Klinikum München-Bogenhausen, Englschalkingerstr. 77, W-8000 München 81, FRG.

\section{IDF Satellite Symposium: Controversies in Diabetic Neuropathy}

This symposium will be held on June 29-Juli 3, 1991 in New York. Chairman: Dr. J.D. Ward, Royal Hallamshire Hospital, Sheffield,
UK. For further information please contact: Ms. E. Mandel, Academy Professional Information Services, Inc. 116 West 32nd Street, New York, N. Y.10001, USA.

\section{Post EASD Symposium: Biochemistry and Biophysics of Insulin Secretion}

This symposium will be held on September 15-18, 1991 at the University of Ulcester, Coleraine, UK. Topics include: Metabolism, ion channels, calcium, phospholipids, nucleotides, protein kinases, biosynthesis, cell interactions, glucose toxicity, diabetic Beta-cell, actions of nutrients, peptides, neurotransmitters and drugs. For further details please contact: Prof. Peter R. Flatt, Biomedical Sciences Research Centre, University of Ulster, Coleraine, Northern Ireland, BT52 1SA, UK. Tel: (+ 44) 0265-44141, Fax: (+ 44) 026540906. 